University of Nebraska - Lincoln

DigitalCommons@University of Nebraska - Lincoln

Faculty Publications from the Harold W. Manter Laboratory of Parasitology

$12-1976$

\title{
Ultrastructure of the Sporocyst Wall during Excystation of Isospora endocallimici
}

Clarence A. Speer

University of Montana

Alan A. Marchiondo

University of New Mexico

Donald W. Duszynski

University of New Mexico, eimeria@unm.edu

Sharon K. File

Tulane University

Follow this and additional works at: https://digitalcommons.unl.edu/parasitologyfacpubs

Part of the Parasitology Commons

Speer, Clarence A.; Marchiondo, Alan A.; Duszynski, Donald W.; and File, Sharon K., "Ultrastructure of the Sporocyst Wall during Excystation of Isospora endocallimici" (1976). Faculty Publications from the Harold W. Manter Laboratory of Parasitology. 122.

https://digitalcommons.unl.edu/parasitologyfacpubs/122

This Article is brought to you for free and open access by the Parasitology, Harold W. Manter Laboratory of at DigitalCommons@University of Nebraska - Lincoln. It has been accepted for inclusion in Faculty Publications from the Harold W. Manter Laboratory of Parasitology by an authorized administrator of DigitalCommons@University of Nebraska - Lincoln. 


\title{
ULTRASTRUCTURE OF THE SPOROCYST WALL DURING EXCYSTATION OF ISOSPORA ENDOCALLIMICI
}

\author{
Clarence A. Speer, ${ }^{*}$ Alan A. Marchiondo, $\dagger$ Donald W. Duszynski, $\dagger$ and Sharon K. File
}

ABSTRACT: Sporocysts of Isospora endocallimici, a parasite of marmosets, were exposed to minimal essentials medium (MEM) or a trypsin-bile salt solution (TBS) and then fixed and prepared for transmission electron microscopy. Excystation occurred in TBS but not MEM. The sporocyst wall has 2 layers, a thin outer layer ( 15 to $110 \mathrm{~nm}$ thick) and a thick inner layer (65 to $180 \mathrm{~nm}$ thick), which is composed of 4 separate curved plates. The outer layer consists of 1 to 3 membranes interspersed with lipid droplets. In the inner layer, a thin layer of material connects the peripheral margins of 2 apposing plates. Immediately beneath this layer, a thin strip of material is interposed between the 2 apposing plates. Ultrastructural changes preparatory to excystation occur primarily in the inner layer of the sporocyst wall. The TBS acts upon the site of apposition between 2 plates causing the interposed strip to swell and separate from the margin of each plate which leads to collapse of the sporocyst. As the sporocyst collapses, the margins of each curved plate curl inward toward the center of the sporocyst.

The details of in vitro excystation of various species of Eimeria and Isospora have been reported. However, the ultrastructural changes that occur in the sporocyst during excystation have been described in only E. callospermophili and E. larimerensis (Roberts et al., 1970) from the Uinta ground squirrel and I. canis (Speer et al., 1973) from dogs. A description of the ultrastructural changes that occur in the sporocyst wall during excystation of Isospora endocallimici, a parasite of marmosets, is reported herein.

\section{MATERIALS AND METHODS}

Oocysts of $I$. endocallimici, obtained from the marmoset, Callimici goeldii, were sporulated at 21 to $22 \mathrm{C}$ and then stored at 4 to $5 \mathrm{C}$ in $2.5 \%$ aqueous (w/v) $\mathrm{K}_{2} \mathrm{Cr}_{2} \mathrm{O}_{7}$ solution. A suspension of oocysts was ground in a motor-driven Teflon-coated tissue grinder to break the oocyst walls, added to either a $0.25 \%(\mathrm{w} / \mathrm{v})$ trypsin (1:250 Difco) $-0.75 \%$ (w/v) sodium taurocholate (N.B. Co., Cleveland, Ohio) solution or minimal essentials medium (GIBCO, Grand Island, N.Y.), and incubated at $37 \mathrm{C}$ for $10 \mathrm{~min}$. Each suspension was then mixed with a suspension of Detroit-6 (American Type Culture Collection, Rockville, MD) cells obtained by treatment of monolayer cultures with a trypsinversene solution. The cells were necessary to form a pellet of sporocysts. After the suspension was centrifuged at $850 \mathrm{~g}$ for $10 \mathrm{~min}$, the pellet was fixed in Karnovsky's fluid (Karnovsky, 1965), 3\% or $15 \%(\mathrm{w} / \mathrm{v})$ glutaraldehyde in $0.2 \mathrm{M}$ cacodylate

Received for publication 3 February 1976.

* Department of Microbiology, University of Montana, Missoula, Montana 59801.

$\dagger$ Department of Biology, University of New Mexico, Albuquerque, New Mexico 87131.

¥Delta Regional Primate Research Center, Tulane University, Covington, Louisiana 70433. buffer, placed in $1.5 \%$ (w/v) $\mathrm{OsO}_{4}$ for $2 \mathrm{hr}$, dehydrated in ethanol and 2 changes of propylene oxide, and embedded in Epon 812 or Spurr's medium (Spurr, 1969). Sections were stained with uranyl acetate and lead citrate and examined with a Corinth 275 or Zeiss EM 9S2 electron microscope.

\section{RESULTS}

We were unable to study the ultrastructure of intact sporocysts due to the resistance of these structures to the effects of the chemical fixatives and the consequent lack of proper infiltration of the embedding medium. Proper fixation and embedding were obtained in specimens apparently disrupted during grinding and in those exposed to the excysting fluid. The sporocyst wall has two layers, a thin outer layer ( 15 to $110 \mathrm{~nm}$ thick) and a relatively thick inner layer (65 to $180 \mathrm{~nm}$ thick) (Figs. 2-7). The outer layer, which appears loosely applied to the surface of the inner layer, consists of one to three unit membranes interspersed with light staining spheroid bodies ( 25 to $100 \mathrm{~nm}$, Figs. 4, 7), similar in appearance to lipid droplets. Regardless of the plane of section, the inner layer is interrupted at two or four places (Fig. 1), thus appearing to consist of four separate curved plates. A liplike thickening ( 150 to $180 \mathrm{~nm}$ thick, Figs. 2-7) is located at the margin of each plate. In some specimens, regular striations are seen in the inner layer which consist of alternating bands ( $\sim 5 \mathrm{~nm}$ thick) of electron-dense and -lucent material perpendicular to the surface of the sporocyst. Such striations are larger and more evident in the liplike margins close to the site of apposition between two plates (Figs. 4, 5). 


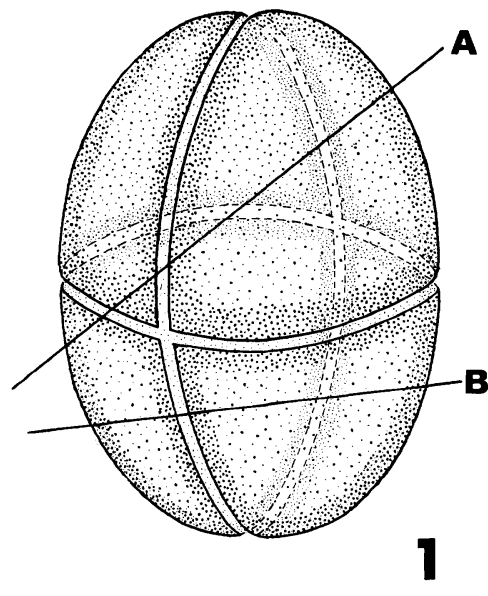

FIGURE 1. Schematic representation of the arrangement of the 4 curved plates in the inner layer of an intact sporocyst wall of Isospora endocallimici; planes of section through the sporocyst at lines A and B would have 4 and 2 sites of apposition, respectively.

A prominent electron-lucent line and an electron-dense terminal band (Figs. 2-5) are located adjacent to each site of apposition; these are more evident and slightly thicker in specimens exposed to the excysting fluid than in unexposed specimens. A thin strip of electrondense material is interposed between the liplike thickenings of two apposing plates (Figs. 2-5). Immediately above this strip, a thin layer of material (Figs. 2-5) connects the two apposing plates which is thicker in untreated specimens than in specimens treated with excysting fluid. In untreated specimens, the interposed strip is $\sim 20 \mathrm{~nm}$ thick, whereas in treated specimens it is $\sim 35 \mathrm{~nm}$ thick, indicating that the strip had swollen during exposure to the excysting fluid. The first indication of the separation of two apposing plates, which apparently leads to collapse of the sporocyst, occurs in the peripheral portion of each site of apposition where the interposed strip swells and a space appears on either side (Fig. 2). Swelling of the interposed strip and the appearance of the surrounding space apparently progress medially toward the center of the sporocyst until the space completely surrounds the swollen interposed strip (Fig. 3). The space (Fig. 4) on one or both sides of the interposed strip continues to enlarge until the two apposing plates separate which causes the sporocyst to collapse. During collapse of the sporocyst, that region of the sporocyst wall close to the terminal bands curls inward toward the center of the sporocyst (Fig. 6), eventually forming a coil-like figure (Fig. 7). At this stage the interposed strip separates from both liplike margins of two apposing plates (Fig. 6), it adheres to the liplike margin of one of the plates (Fig. 7) or it is no longer visible.

\section{DISCUSSION}

To date, two distinct patterns of excystation have been found in Isospora. In those isosporans that have sporocysts with Stieda bodies, excystation occurs in a manner similar to that of Eimeria species in which the sporozoites always exit through a gap at one pole of the sporocyst created by dissolution of the Stieda body in the presence of excysting fluid (Duszynski and Brunson, 1972; Speer and Duszynski, 1975). Certain other species of Isospora, such as I. canis (Speer et al., 1973), I. endocallimici (Duszynski and File, 1974), $I$. bigemina and I. arctopitheci (Duszynski and Speer, 1976) have sporocysts without Stieda bodies in which the sporocyst walls collapse during excystation and the sporozoites escape randomly.

The ultrastructure of the sporocyst wall (present study) and the process of excystation of I. endocallimici (Duszynski and File, 1974) as observed with the light microscope are similar to that of $I$. canis (Speer et al., 1973). In electron micrographs of both species, the sporocyst wall appears to consist of a thin outer layer and a thick inner layer, the latter being interrupted at four sites. During excystation, the inner wall collapses into four pieces. Speer et al. (1973) suggested that the slight thickening (not seen in I. endocallimici) observed in the groove of the outer layer of $I$. canis sporocysts might be especially susceptible to the action of the trypsin-bile salt excysting fluid, resulting in splitting of the outer layer which allowed the inner layer to break into four plates. In the inner layer of the sporocyst wall of $I$. endocallimici, the material connecting the peripheral border of the liplike margins of two apposing plates decreased in thickness, the interposed strip between two plates swelled slightly and separated from the liplike margin of each plate, evidently causing collapse of the 


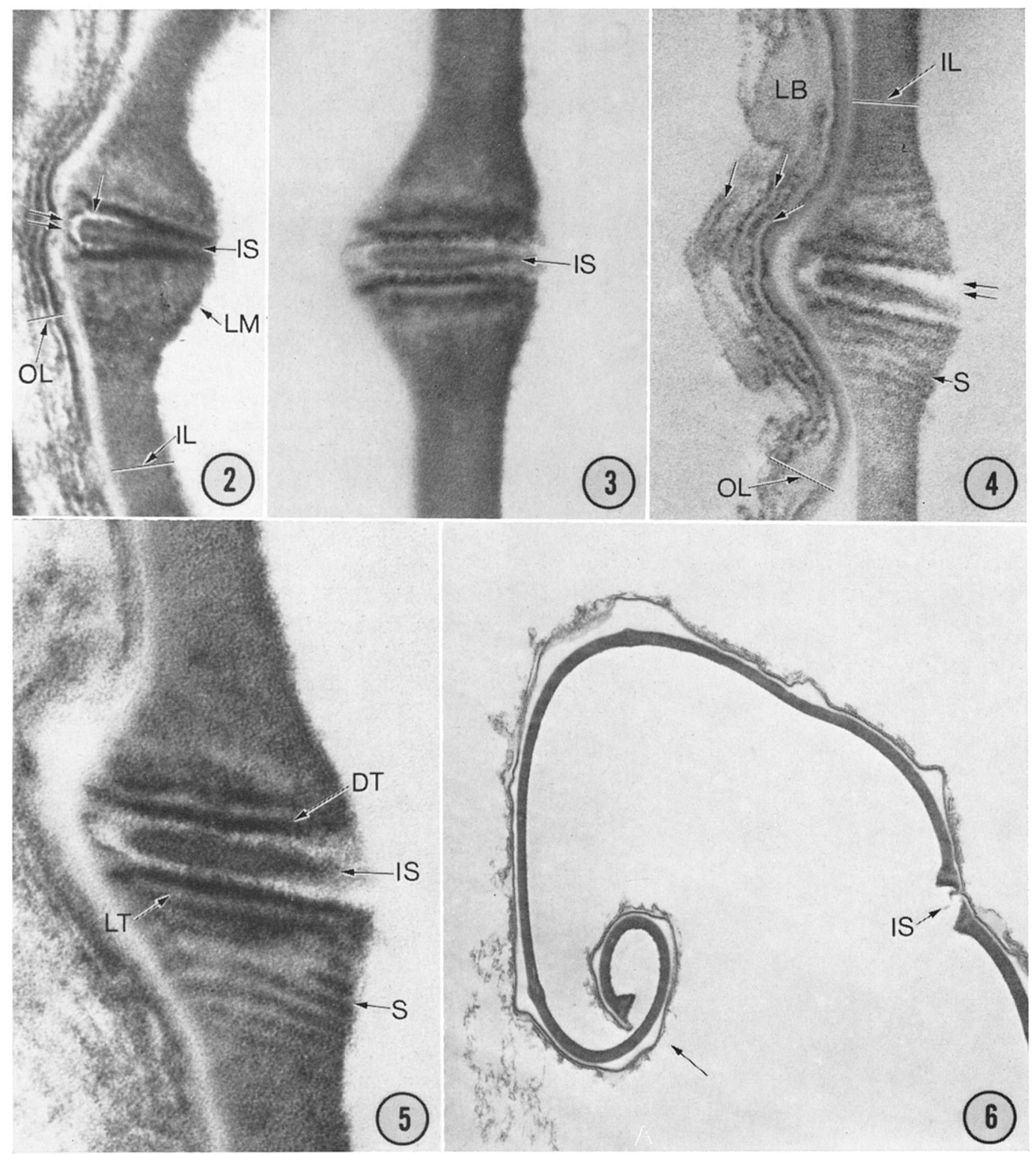

Figures 2-7. Electron micrographs of the sporocyst wall of Isospora endocallimici; 20 min after exposure to a trypsin-bile salt excysting medium; Figs. 2-5. Site of apposition between 2 plates of the inner layer of the sporocyst wall; Fig. 6. Sporocyst wall in process of collapsing; 2. Site of apposition between 2 plates; note outer (OL) and inner (IL) layers, space (arrow) surrounding the swollen peripheral portion of interposed strip (IS), thin strip (double arrow) above IS, and liplike margins (LM) of inner layer. $\times 131,000$. 3. The interposed strip is completely surrounded by a space; outer layer is absent. $\times 131,000$. 4. Interposed strip has started to separate (double arrow) from one liplike margin; note membranes (single arrows) and lipid bodies (LB) in outer layer, and striations (S) in liplike margins of inner layer. $\times 131,000$. 5. Light $(\mathrm{LT})$ and dense (DT) terminal bands are visible adjacent to space surrounding interposed strip. $\times 252,000$. 6. Plate of sporocyst wall in initial stage of collapse; note inward curling of one margin (arrow) and that at the other margin the interposed strip has separated from each of the 2 apposing plates. $\times 10,700$. 


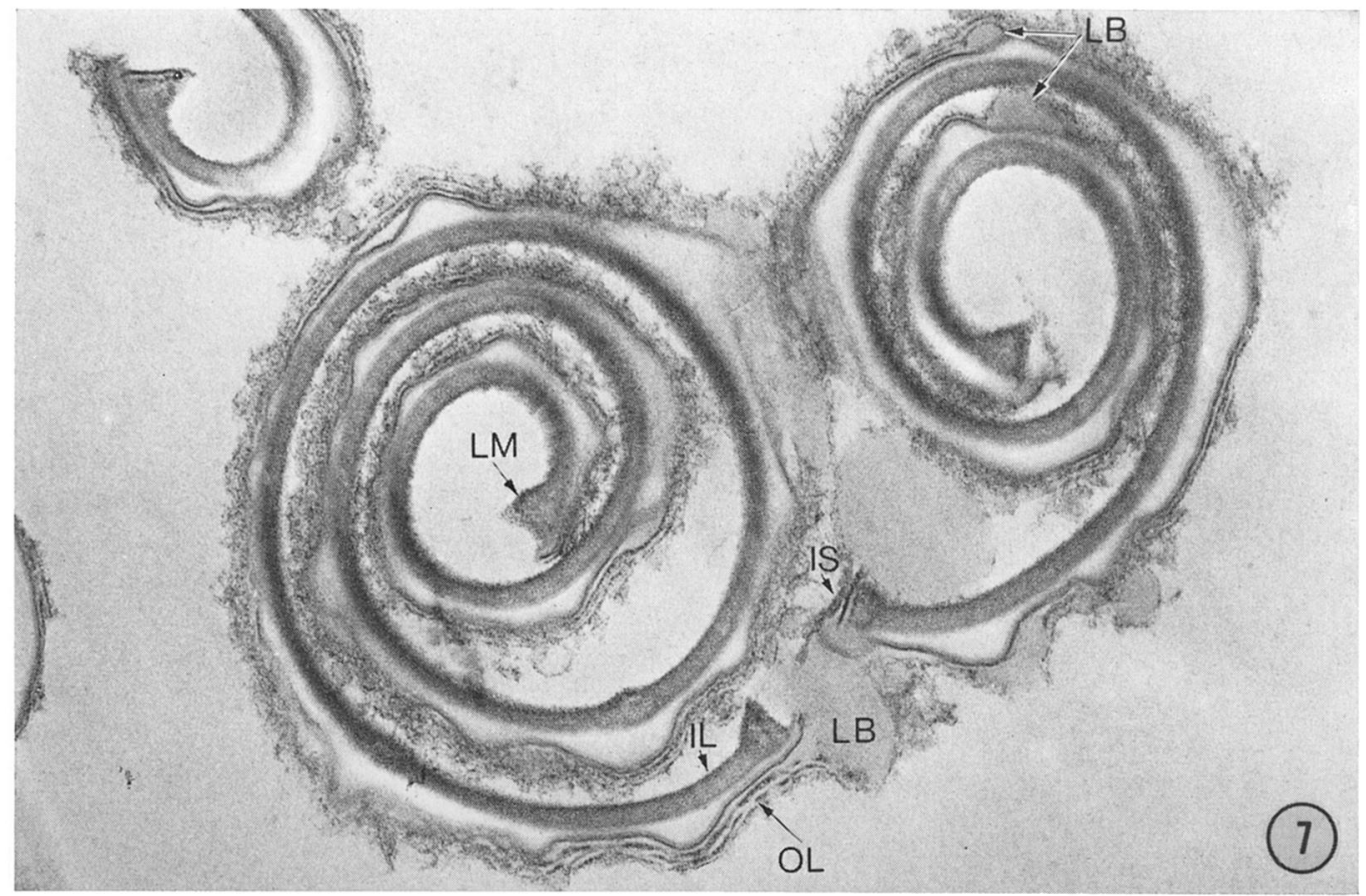

Figure 7. Two collapsed sporocyst walls. $\times 55,700$.

sporocyst. A similar interposed strip of material occurs in the sporocysts of $I$. canis (Speer, unpublished data). Thus, in $I$. canis and $I$. endocallimici, the material connecting the outer margins of two apposing plates and the interposed strip between two such plates might be analogous in function to the Stieda and substiedal bodies, respectively, which are present in sporocysts of Eimeria and certain Isospora species.

\section{LITERATURE CITED}

Duszynski, D. W., and J. T. Brunson. 1972. The structure of the oocyst and the excystation process of Isospora marquardti sp. $\mathrm{n}$. from the Colorado pika, Ochotona princeps. J Protozool 19: 257-259.

- AND S. K. FILE. 1974. Structure of the oocyst and excystation of sporozoites of Isospora endocallimici n. sp., from the marmoset Callimici goeldii. Trans Am Microsc Soc 93: 403-408.

AND C. A. SpeEr. 1976. Excystation of
Isospora arctopitheci Rodhain, 1933 with notes on a similar process in Isospora bigemina (Stiles, 1891) Luke, 1906. Z Parasitenk 48 : 191-197.

Karnovsky, M. J. 1965. A formaldehyde-glutaraldehyde fixative of high osmolality for use in electron microscopy. J Cell Biol 27: 137A138A.

Roberts, W. L., C. A. SpeEr, and D. M. HaMMOND. 1970. Electron and light microscope studies of the oocyst walls, sporocysts, and excysting sporozoites of Eimeria callospermophili and E. larimerensis. J Parasitol 56: 918926.

Speer, C. A., And D. W. Duszynski. 1975. Fine structure of the oocyst walls of Isospora serini and Isospora canaria and excystation of Isospora serini from the canary, Serinus canarius L. J Protozool 22: 476-481.

, D. M. Hammond, J. L. Mahrt, and W. L. RoberTs. 1973. Structure of the oocyst and sporocyst walls and excystation of sporozoites of Isospora canis. J Parasitol 59: 35-40.

Spurr, A. R. 1969. A low viscosity epoxy resin embedding medium for electron microscopy. J Ultrastruct Res 26: 31-43. 